\title{
ROLE-TAKING. EL PONERSE EN LUGAR DE OTRO COMO HECHO Y VIRTUD EPISTÉMICA (DE SUSTITUCIÓN A SUPLANTACIÓN)
}

\author{
ROLE-TAKING AS FACT AND EPISTEMIC VIRTUE (FROM SUBSTITUTION \\ TO IMPERSONATION)
}

\author{
AliCIA DE Mingo RoDRÍGUEZ \\ Universidad de Sevilla \\ amingo@us.es
}

RECIBIDO: 9 DE DICIEMBRE DE 2015

ACEPTADO: 22 DE MARZO DE 2016

Resumen: El mecanismo del conocido como role-taking (ponerse en lugar del Otro) no sólo es relevante en el plano del desarrollo psicológico y social del sujeto, sino también por lo que se refiere a su vida cognitiva $\mathrm{y}$, más específicamente, racional y ética. Por ello, debe ser abordado no sólo como un hecho, sino como una virtud epistémica con amplias repercusiones. En el presente artículo abordo cuatro referencias para investigar esta dualidad de hecho-virtud y sus desafíos, a saber: los propios estudios de psicología evolutiva sobre el role-taking, algunas tesis de A. Schütz sobre las construcciones de "sentido común", la dinámica crítica del sensus communis logicus kantiano y las propuestas de S. Benhabib sobre lo que denomina universalismo sustitutivista (con un apunte sobre la ética del discurso habermasiana). En todos los casos, se trata de vigilar que un mecanismo de sustitución no se convierta en una trampa de suplantación del Otro.

Palabras-clave: role-taking, virtud epistémica, sentido común, suplantación, Otro.

Abstract: The mechanism of the so-called role-taking is not only relevant in the psychological and social development of the subject, but also in terms of his cognitive and, more specifically, rational and ethical life. Therefore, it must be approached not only as a fact, but as an epistemic virtue, with wide repercussions. In this article I take four references to investigate this duality of fact-virtue and its challenges, namely the evolutionary psychology studies on 
role-taking, A. Schütz's theses on "common sense"-constructions, the critical dynamics of Kant's sensus communis logicus and the proposals of S. Benhabib on what she calls substitutionalist universalism (with a note on the Habermasian ethics of discourse). In all cases, it is a question of ensuring that a substitution mechanism does not become an impersonation trap of the Other

Key-words: role-taking, epistemic virtue, common sense, impersonation, Other

\section{Introducción}

Cuanto más profunda es mi soledad, tanto más urgente es la necesidad de forjar fantasmas de seres racionales con los que debo ser solidario

G. Lebrun ${ }^{1}$

"Me pongo en tu lugar", "ponte en mi lugar", o incluso, más complejamente, "no te pones en lugar de"... En general, el "ponerse en el lugar del Otro" resuena en nuestros oídos como un desafío al mismo tiempo cognitivo (incluso más precisamente: epistémico) y ético, a la vez que como una reivindicación y un mérito. Antes de considerarlo como una acción a realizar, sin embargo, por lo que se refiere a su génesis psicológica se trata de un dinamismo del desarrollo cognitivo pre-epistémico que se produce de forma "natural", casi como un hecho que no requiriese de una acción "voluntariosa" ni de un esfuerzo especiales; hablaré de ello más adelante. En cualquier caso, cuando el agente es adulto, presentándoseles como ya diferenciados el Yo y el Otro y sus respectivas perspectivas, se trata, en efecto, de un dinamismo que debe contar con una capacidad que se convierte en esfuerzo, ganando así la cualificación de mérito epistémico y ético, pues aunque la capacidad se alcanza de hecho a una edad relativamente temprana (de lo que ha dado buena cuenta la psicología evolutiva),

\footnotetext{
${ }^{1}$ LEBRUN, Gérard: Kant y el final de la metafísica. Ensayo sobre la Crítica del juicio, Escolar y Mayo, Madrid, 2008, pág. 368.
} 
luego, el ejercicio concreto del "ponerse en lugar del Otro" ya no resulta una práctica tan obvia o que "vaya de suyo", viable ni cómoda, como todos bien sabemos y experimentamos casi cotidianamente. De entrada, más bien se nos presenta como un desafío cognitivo-epistémico en la medida en que resulta casi inconcebible una orientación racional, y no meramente psicológica, sin esa suerte de "ponerse en el lugar de" o -si se me autoriza este término- "substitución" como virtud racional. En efecto, si hubiera que caracterizar prima facie el ámbito de incumbencia del role-taking, habría que reconocer que es formalcognitivo. Quizás uno de los mejores ejemplos de este basamento eminentemente cognitivo fuese el de una partida de ajedrez, en la que los jugadores tienen continuamente que intentar ponerse en el lugar de los posibles y mejores movimientos que el contrincante podría llevar a cabo, en respuesta a los propios, y éstos en respuesta a los del contrincante, condicionando este vaivén y la evaluación de las mejores posibilidades de los jugadores la motivación del propio juego. Los movimientos de cada jugador son acciones y reacciones de role-taking a los del rival. Que en primer lugar el role-taking sea ante todo un "mérito" cognitivo-epistémico, más que "ético" se muestra en el caso, por ejemplo, de un acosador o un timador, que debe ponerse en lugar de su víctima ( $\mathrm{y}$ a veces del modo más sofisticado) para alcanzar éxito en su engaño. Sin embargo -preciso es reconocerlo-, en nuestra vida cotidiana son innumerables las ocasiones en que el desafío se presenta también, y no secundariamente, bajo un aspecto ético, en la medida en que se exige un cuestionamiento del punto de vista del ego (o de la comunidad) que coincide con una actitud de respeto previo hacia el Otro en la que se haya reconocido su pleno derecho a ser estimado como poseyendo un punto de vista no sólo diferente, sino incluso posiblemente opuesto al propio (individual $\mathrm{y} / \mathrm{o}$ comunitario). 
En este breve estudio, quisiera mostrar un desarrollo que abarca desde la adquisición del role-taking como capacidad psicológica (apartado I) y la adopción del punto de vista del Otro como una adquisición semi-pasiva o "de sentido común" (II), hasta el roletaking como un esfuerzo y mérito racionales (a partir de Kant, apartado III), capaz de acceder al Otro en su concreción y diferencia (siguiendo una importante sugerencia de Benhabib) (apartado IV). Para concluir, me gustaría proponer una reflexión de carácter general acerca de algunas prácticas relativas al role-taking que creo de interés en el marco general de entrecruzamiento entre teoría del conocimiento y de la acción racional, epistemología y ética. Para ello, el marco que brinda el proyecto de la Filosofía aplicada me parece idóneo y muy estimulante.

\section{Superando el egocentrismo (por el momento). Primeros pasos}

En general, nuestro conocimiento previo de la diferencia del Otro, e incluso de su alteridad, que ya presuponemos siquiera en sus niveles más básicos en la vida cotidiana, depende de que la posibilidad de "ponerse en lugar del Otro" se haya acreditado previamente en un terreno psicológico, acorde al desarrollo cognitivo del niño. La expresión "role-taking", procedente de la psicología evolutiva, designa una capacidad que aparece en un momento temprano, estudiado concienzudamente, en el que el niño se "descentra", es decir, comienza a distinguir su punto de vista como ego del punto de vista del Otro, porque antes de esa distinción aún no han aparecido con suficiente nitidez psicológica. El egocentrismo primario no reconoce, en principio, al Otro, es decir: la posibilidad de que el Otro pueda tener una perspectiva diferente de la propia, e incluso contraria o "rival". La psicología aborda esta problemática con sus propios medios, por más que se trata de un tema que la filosofía trascendental y fenomenológica, y 
otros puntos de vista filosóficos, como la ética del discurso habermasiana, han estudiado con enorme interés por sus presupuestos y sus enormes rendimientos.

El asunto en liza es el egocentrismo infantil (luego aparecerá el egocentrismo adulto) en la etapa "preoperacional" y su superación. En su momento -no quisiera entretenerme en ello-, los estudios de Mead y Werner, pero sobre todo de Jean Piaget, fueron decisivos en este aspecto. Las primeras investigaciones de este último datan de 1923 (El lenguaje y el pensamiento del niño). Muchos de sus trabajos sobre el habla o el desarrollo de la inteligencia fueron cruciales. Pues bien, en relación al tema que nos ocupa podríamos hablar no ya de "egocentrismo" sino, siguiendo a Piaget, de "centración", que se caracteriza por un comportamiento y habla "monológicos". El niño no "contempla" la posibilidad de un Otro que, por ejemplo, no compartiese sus conocimientos o tuviera una perspectiva diferente. Aquí no me ocuparé de pormenores relativos a la edad en que se desarrolla y se abandona el núcleo duro del egocentrismo o la centración, adquiriéndose progresivamente la capacidad de role-taking. Como resume Marchesi (me gustaría que leyésemos este texto haciendo caso omiso de que está hablando de niños muy pequeños):

la centración hace referencia a la tendencia constante en el nivel preescolar a considerar un solo punto de vista de los varios posibles o a fijar su atención en un aspecto de los objetos o situaciones sin tener en cuenta otros aspectos importantes de la situación, lo que conduce a un razonamiento distorsionado. Este fracaso para descentrar impide comprender cómo los cambios en dos dimensiones pueden compensarse uno al otro. De la misma forma, el fracaso para descentrar en una dimensión temporal se manifiesta en la incapacidad de realizar transformaciones, aspecto central del

${ }^{2}$ MARCHESI, Álvaro: "El pensamiento preoperatorio", en PALACIOS, Jesús, MARCHESI, Álvaro y CARRETERO, Mario (comps.): Psicología evolutiva 2. Desarrollo cognitivo y social del niño, Alianza Editorial, Madrid, 1985, págs. 187 y ss. 
pensamiento preoperatorio. Los niños de estas edades no son capaces de situarse en el punto de vista o la perspectiva de los otros y están convencidos de que su propia perspectiva coincide con la de los demás ${ }^{3}$

La literatura en el ámbito de la psicología evolutiva se ha ocupado mucho de evaluar las edades de la centración-descentramiento y de proponer experimentos diversos para comprender las dificultades del niño en este sentido. Selman resumió en cinco niveles la capacidad para situarse en una "perspectiva social", que abarcan la infancia y la adolescencia. El primero de tales niveles (3-6 años) es eminentemente egocéntrico: no se es capaz de adoptar un punto de vista diferente vinculado a Otro u Otros. En este experimento, que represento mediante un esquema

\section{OBJETO 3 MUÑECO $($ mira $\rightarrow$ )}

\section{OвJеTO 1}

\section{OBJETO 2}

Se trata de detectar si el infante ha alcanzado un nivel de maduración intelectual suficiente para ponerse en el lugar de Otro. Si se pregunta al niño protagonista del experimento cuántos objetos ve el muñeco que en el diagrama mira a la derecha, y responde que 2, ello significará que se ha puesto en su lugar, mientras que si dice 3 , es que aún no se ha descentrado en favor del muñeco. Pues bien, esta posibilidad incipiente de ponerse en el lugar del Otro es decisiva para avanzar en el terreno de la racionalidad, no importa si pragmática (recordemos el caso del vendedor que se pone en el lugar del consumidor) o eminentemente ético-dialógica.

En el segundo nivel (de 6 a 8 años) el niño comienza a distinguir entre su perspectiva y la de los Otros, potencialmente diferente. Sin embargo, no es capaz de manejar a la vez las dos perspectivas ni -lo cual resulta decisivo- de considerarse a sí mismo tal como el Otro le ve, le toma en consideración o le juzga.

${ }^{3}$ Ibid., pág. 188. 
En el tercer nivel (entre 10 y 12 años) se alcanza la simultaneidad de puntos de vista diversos y ya se asume propiamente que el Otro puede tener otro conocimiento diferente del nuestro, e incluso contrario. En un cuarto nivel (de 12 a 15 años), llega el momento de comprender lo que Mead denominó "Otro generalizado". Ya no se trata simplemente de tal o cual Otro, sino de la perspectiva genuinamente social. Es entonces cuando tiene lugar el encuentro con el todo social y, por tanto, se amplía la funcionalidad del roletaking. En el quinto nivel (a partir de los 15 años), el adolescente comprende la relatividad de las perspectivas tal como las hace posible la sociedad en su conjunto y se atisba que el role-taking es posible y practicable fuera del entorno social al que pertenece. Surge en este momento la perspectiva multi- e intercultural ${ }^{4}$. La importancia de estos niveles (y de su estudio) de cara a valorar el desarrollo de las nociones y evaluación de las experiencias en el terreno de la justicia y de la amistad resulta indiscutible ${ }^{5}$.

Quisiera destacar ya -por más que pueda parecer un detalle sin mayor relevancia- que uno de los aspectos de esta problemática que me parece más interesante es aquel en el que al sujeto adulto se le pide que se ponga en lugar de un niño que aún no es capaz del roletaking, por las implicaciones que ello tiene para el trato con el niño, el éxito o fracaso en el proceso educativo, etc. En enorme medida, ese trato es responsabilidad del adulto, de modo que si no se evalúa con suficiente "tacto" la circunstancia de irreciprocidad (tal es el asunto en liza), no alcanzaremos una situación de trato adecuado y eficaz con el niño. Cuando éste consiga descentrarse, se habrá llegado a la situación racional de una reciprocidad que podrá

\footnotetext{
${ }^{4}$ SELMAN, Robert L.: "Taking another's perspective: Role-taking development in early childhood”, en Child Development, volumen 42, 1971. Págs. 1721-1734; cit. por MARCHESI, Álvaro: "El conocimiento social de los niños", op. cit., pág. 332.

${ }^{5}$ MARCHESI, Álvaro: "El conocimiento social de los niños", op. cit., págs. 333334.
} 
conducir a la culminación del proceso comunicativo eminentemente racional.

\section{Reciprocidad de perspectivas y common sense. El "estar ya puestos en el lugar del Otro" (A. Schütz)}

Basándose en buena medida en las investigaciones fenomenológicas de Husserl en torno a la intersubjetividad ${ }^{6}$, Alfred Schütz se propuso, en general, explorar a fondo lo que consideraba que no había sido suficientemente explorado por Husserl, a saber, lo que sería una fenomenología de las construcciones sociales de "sentido común" y una fenomenología de la actitud natural, a sabiendas de que es en ese terreno donde se arraiga nuestro compromiso fenomenológico-comprensivo con la realidad. Con su estudio en torno a la fenomenología del sentido común, Schütz prestó un importante servicio a lo que sería su fenomenología comprensiva o incluso hermenéutica (en una línea que difería claramente de la heideggeriana).

En concreto, por lo que a nuestro propósito en este artículo se refiere, Schütz nos ofrece abundantes recursos para pensar a fondo el role-taking con su teoría acerca de lo que denominó tesis general de reciprocidad de perspectivas. Con ella no pretendía que esa reciprocidad se erigiese en una especie de método. No se trata, en verdad, de un procedimiento a realizar, sino de algo que ya tiene lugar en la cotidianeidad, funcionando casi, por así decirlo, como un "automatismo". Lo que está en juego es el sentido común en el que ya nos encontramos y del que participamos.

A juicio de Schütz, dicha "tesis" se descompone en dos idealizaciones que, insisto, son ya operativas en el sentido común:

\footnotetext{
${ }^{6}$ Buena parte de los textos breves de Schütz sobre Husserl se encuentran en la segunda parte de SCHÜTZ, Alfred: El problema de la realidad social (ed. a cargo de NATASON, M.), Amorrortu, Buenos Aires, 1974, págs. 111 y ss.
} 
la de la intercambiabilidad de puntos de vista y la de la idealización de la congruencia en los sistemas de significatividades. Pues bien, para comprender la primera de estas idealizaciones se ha de considerar que

el sector del mundo a mi alcance actual está centrado alrededor de mi Aquí, y el centro del mundo al alcance actual de mi semejante alrededor del suyo, que es, visto desde mi Aquí, un Allí. Ambos sectores pueden intersectarse parcialmente, y algunos de los objetos, hechos y sucesos del mundo externo pueden estar a mi alcance actual y al de mi semejante, y hasta dentro de su zona manipulatoria y la mía. Sin embargo, tal objeto, hecho o suceso tendrá una apariencia diferente en cuanto a dirección, distancia, perspectiva, sombreado, etc., visto desde el centro de mis coordenadas, llamadas Aquí, y desde las suyas, llamadas Allí. Ahora bien: un axioma básico de toda interpretación del mundo común y sus objetos es que estos diversos sistemas coexistentes de coordenadas pueden ser transformados unos en otros; doy por sentado -y presupongo que mi semejante hace lo mismo- que yo y él tendríamos típicamente las mismas experiencias del mundo común si cambiáramos nuestros lugares, de tal modo que mi Aquí se transformara en el suyo, y su Aquí -que para mí es ahora un Allí- en el mío ${ }^{7}$

La "intercambiabilidad" se presenta como una acción que ya se realiza "sin más", espontánemente. Es “operativa", pero funciona como un presupuesto o como un automatismo. Nos ponemos, me pongo ya, de entrada, en el lugar del Otro, fundándose de este modo pasivo el mundo "familiar" y común, que a su vez ya está

7 SCHÜTZ, A.: "Símbolo, realidad y sociedad", en SCHÜTZ, A.: El problema de la realidad social, Amorrortu, Buenos Aires, 1974, págs. 282-283. Symbol, Reality and Society apareció por vez primera en BRYSON, LYMAN, FINKELSTEIN, Louis, HOAGLAND, HUDSON y MACIVER, R.M. (eds.): Símbolos y Sociedad. Actas del $14^{\circ}$ Simposium de la Conferencia sobre Ciencia, Filosofía y Religión, Harper, New York, 1955. Es importante valorar la fecha, porque algunas de las investigaciones de Schütz, que sin duda conocía el pensamiento heideggeriano, preceden a la gran aportación a la hermenéutica que supone Verdad y método, de Gadamer, que aparece en 1960. 
presupuesto. La idealización que se opera es pragmáticohermenéutica. Se trata del basamento no sólo de nuestra pertenencia a tal comunidad, tradición o sociedad, sino de nuestra participación en ella, en la medida en que debemos asumirlo comprensivamente. La distinción entre pertenencia y participación es importante, más allá de Schütz, en la medida en que podemos pertenecer a una sociedad pero sin participar comprensivamente en ella (lo que es una importante fuente de desarraigo e incluso conflicto, por ejemplo, en el caso de problemáticas vinculadas a la multiculturalidad).

Por tanto, insisto en ello, Schütz no aborda esta idealización como un desafío, sino como un haber previo, un "hecho". Eso sí, cabe hablar de "idealización" en la medida en que actúa como un presupuesto que, de entrada, no cuestionaremos salvo que se plantee alguna situación problemática. No se trata de que racional y/o éticamente se me conmine a "ponerme en lugar de Otro", sino de que ya estoy/estamos puestos, de entrada y sin cuestionamiento previo, en el lugar del Otro. Aunque Schütz lo formule en términos de espacialidad, lo que está en juego son los puntos de vista o perspectivas. Los Otros "familiares", "con-vecinos" son aquellos con los que es máximamente eficaz aquella idealización. Y será considerado (o se considerará a sí mismo) extraño aquel que, ajeno al sentido común compartido, no se presente como pudiendo compartir de entrada esa "intercambialidad".

Si esta idealización pertenece al orden de la acción que pasivamente tiene lugar, la segunda de las idealizaciones, la de la congruencia en el sistema de significatividades, aclara sobre la base de qué trasfondo dicha "acción pasiva" es posible. A juicio de Schütz,

cada uno de nosotros (...) se encuentra en una situación biográficamente determinada única, y por esta misma razón es inevitable que difieran mi propósito y el de mi semejante, así como los sistemas de significatividad que se originan en ellos. Pero, con carácter de otro axioma básico, doy 
por sentado hasta que se pruebe lo contrario $-\mathrm{y}$ presupongo que mi semejante hace lo mismo- que las diferencias originadas en nuestros sistemas privados de significatividades pueden ser dejadas de lado para el propósito inmediato y que yo y él, nosotros, interpretamos los objetos, hechos y sucesos actual o potencialmente comunes de una manera "empíricamente idéntica", es decir, suficiente para los fines prácticos $^{8}$

En un texto anterior a Símbolo, realidad y sociedad, de 1953, "El sentido común y la interpretación científica de la acción humana", Schütz ya había explicado cómo el ámbito del mundo compartido (nosotros) que aquella intercambiabilidad y esta congruencia hacen posible es un ámbito "objetivo" y "anónimo", es decir, "separado e independiente de mi definición de la situación y la de mi semejante, de nuestras circunstancias biográficas exclusivas y de los propósitos reales y potenciales inmediatos que ellas involucran" ". Debemos retener esta puntualización porque, cuando más adelante tomemos en consideración la aportación de $\mathrm{S}$. Benhabib, comprobaremos cómo esta pensadora demandará como un imprescindible logro a alcanzar el que el sujeto acceda a la concreción y encarnación de la situación de comunicación y del Otro. Benhabib da, digamos, un paso atrás, que en verdad supone un paso adelante, en el sentido de aspirar a reintegrar la singularidad de los agentes o participantes al proceso del roletaking y de las posibilidades de acuerdo y diálogo que hacen posible, en tanto ya no resulte obvia la eficacia del automatismo. De este modo, se plantearía la necesidad de una revisión del (ahora

\footnotetext{
${ }^{8}$ Ibid., pág. 283. Vid. también, y para más detalle, "El sentido común y la interpretación científica de la acción humana", en ibid., págs. 42 y ss.

9 SCHÜTZ, Alfred: "Common-Sense and Scientific Interpretation of Human Action" apareció en 1953 en el vol. 4 de Philosophy and Phenomenological Research.

${ }^{10}$ SCHÜTZ, Alfred: "El sentido común y la interpretación científica de la acción humana", op. cit., pág. 43.
} 
solamente presunto) sentido "común". Más adelante me referiré a ello con algo más de detalle. Para Schütz,

lo que se supone conocido por todo el que comparta nuestro sistema de significatividades es el modo de vida que los miembros del endogrupo consideran natural, bueno y correcto; como tal, está en el origen de las diversas recetas para manejar cosas y hombres con el fin de enfrentar situaciones tipificadas, de los usos y costumbres, de la "conducta tradicional", en el sentido que daba Max Weber a esta expresión, de los "enunciados obvios" que el endogrupo cree válidos a pesar de ser "inconsistentes"; en resumen, del "aspecto natural relativo del mundo" 11

Es muy importante esa puntualización que plantea Schütz, en el sentido de que la validez no excluyese la inconsistencia, pues de lo que se trata en el sentido común es de una validez justamente endogrupal, sin implicar pregunta alguna acerca de la validez. epistémica o la legitimidad ética. Para Schütz,

cuanto más anónima es la construcción tipificadora, tanto más alejada está de la singularidad del semejante individual implicado y tanto menores son los aspectos de su personalidad y pautas de conducta que entran en la tipificación como significativos respecto del propósito a mano para el cual ha sido construido el tipo. Si distinguimos entre tipos generales (subjetivos) y tipos de cursos de acción (objetivos), podemos decir que la creciente anonimia de la construcción conduce al reemplazo de los primeros por los segundos. En la anonimia completa, se supone que los individuos son intercambiables, y el tipo de curso de acción se refiere a la conducta de "cualquiera" que actúe de la manera definida como típica por la construcción ${ }^{12}$

\footnotetext{
${ }^{11}$ Idem.

${ }^{12}$ Ibid., pág. 47. En Ser y tiempo había dicho Heidegger que "el arbitrio de los otros dispone de las posibilidades cotidianas del Dasein. Pero estos otros no son determinados otros. Por el contrario, cualquier otro puede reemplazarlos. Lo decisivo es tan sólo el inadvertido dominio de los otros, que el Dasein, en cuanto coestar, ya ha aceptado sin darse cuenta. Uno mismo forma parte de los otros y refuerza su poder. "Los otros" — así llamados para ocultar la propia esencial pertenencia a ellos - son los que inmediata y regularmente "existen" [ "da
} 
Creo que con estas consideraciones, a pesar de su brevedad, queda suficientemente clara la aportación de Schütz al dinamismo del role-taking. La posibilidad de "ponerse en el lugar del Otro" que la psicología evolutiva ya había descubierto se muestra ahora como una suerte de posibilidad "a la mano" en la que de algún modo se hallan sedimentados, en forma y contenidos, aquellos iniciáticos "esfuerzos" (pasivos) infantiles por adoptar el punto de vista de los Otros. Desde su sociología comprensiva, lo que Schütz muestra claramente es que aquella primera expresión del role-taking se consolida como comunidad, sin que el "estar puesto en lugar del Otro" sea abandonado en lo sucesivo, mientras justamente se mantenga estable la comunidad.

Sin embargo, nuestros dos siguientes autores, Kant y Benhabib, nos permitirán considerar que el "ponerse en lugar del Otro" no es meramente un proceso que transcurra pasivamente de una vez por todas, sin deber afrontar ulteriores riesgos y desafíos. Kant confiaba, pero con ciertas precauciones, en que el yo, en efecto, fuese capaz sin más de ponerse en el lugar del Otro, después de

sind"] en la convivencia cotidiana. El quién no es éste ni aquél, no es uno mismo, ni algunos, ni la suma de todos. El "quién" es el impersonal, el "se" o el "uno" [das Man]. / Más arriba se hizo ver que en el mundo circundante inmediato ya está siempre a la mano, como objeto de la ocupación común, el "mundo circundante" público. En la utilización de los medios de locomoción pública, en el empleo de los servicios de información (periódicos), cada cual es igual al otro. Esta forma de convivir disuelve completamente al Dasein propio en el modo de ser "de los otros", y esto, hasta tal punto, que los otros desaparecen aún más en cuanto distinguibles y explícitos. Sin llamar la atención y sin que se lo pueda constatar, el uno despliega una auténtica dictadura. Gozamos y nos divertimos como se goza; leemos, vemos y juzgamos sobre literatura y arte como se ve y se juzga; pero también nos apartamos del "montón" como se debe hacer; encontramos "irritante" lo que se debe encontrar irritante. El uno, que no es nadie determinado y que son todos (pero no como la suma de ellos), prescribe el modo de ser de la cotidianidad" (HEIDEGGER, M.: Ser y tiempo, Trotta, Madrid, 2009, pág. 146). 
haber utilizado este recurso para a su vez desconfiar del yo. De inmediato lo tomaré en consideración. Por lo que se refiere a Benhabib, destacaré su desconfianza respecto a la posibilidad de que los Otros en cuyo lugar debemos ponernos sean sin más reconocidos como tales verdaderamente, sin subterfugios, ni simulacros, ni suplantaciones, justamente en su irreductible singularidad.

\section{Sensus communis logicus como desafío racional (Kant)}

No creo exagerado proponer la teoría kantiana acerca del sensus communis logicus como una pieza clave en la teoría general acerca de la relevancia epistémica y ética del role-taking. Me refiero al sensus communis logicus al que Kant alude en el $\S 40$ de la Crítica del juicio ${ }^{13}$. Se recordará que la primera máxima es la del "pensar por sí mismo", y guarda una estrecha relación con el ideal ilustrado de autonomía (por ejemplo, tal y como se formula, en una de sus versiones más conocidas, en ¿Qué es la Ilustración?). La segunda máxima -objeto prioritario de nuestro interés aquí- la nombra Kant como el pensar en lugar del Otro, de cada Otro, pero -y esta puntualización es crucial- no sólo de cada Otro real, sino también posible. La crítica no debe pasar por alto que si Kant activa esta segunda máxima es a) porque no confía en que fuese suficiente pensar por sí mismo de cara a despegarse de la premisa egocentrista, y b) porque la apelación a todo Otro posible esta tensionada por la exigencia de universalizar el juicio. Ahora bien, este tensionamiento universalizador no es el que decide finalmente, pues la tercera máxima propone un retorno a aquel yo de la primera, sólo que después de pasar por la segunda, de modo que si no fuese posible aquella universalización, el yo al menos habrá

${ }^{13}$ KANT, I.: Crítica del juicio, Espasa-Calpe, Madrid, 1977, págs. 198-201. 
realizado su esfuerzo, debiendo retornar a sí mismo o, como dice Kant, pensar finalmente de acuerdo consigo mismo. Creo que no se repara suficientemente, como cuando, por regla general ocurre, en que supeditamos beneficios a logros, que lo que importa en la segunda máxima es mucho más el esfuerzo a realizar que el éxito que pudiera conseguirse... En alguna otra ocasión me he ocupado de un pasaje de la Antropología desde un punto de vista pragmático en el que Kant llama la atención acerca de la tentación de pasar del Yo al Nosotros sin que en verdad se hubiese realizado el esfuerzo que permitiría emitir legítimamente ese Nosotros, resultando de ello que en lugar de "ponerse en lugar del Otro" lo que hace el yo sería suplantar al Otro. En una "Nota" decía Kant: "Sobre las fórmulas del lenguaje egoísta. El lenguaje en que el Jefe del Estado se dirige al pueblo es, en nuestros tiempos, habitualmente pluralista (Nos, N., por la gracia de Dios, etc.). Cabe preguntar si el sentido no es, empero, más bien egoísta, esto es, si no denuncia la propia autoridad soberana $y$ no significa exactamente lo mismo que el Rey de España dice con su Yo, el $R e y^{\prime 14}$. Esta observación, que bien podría figurar a pie de página en el $\S 40$ de la Crítica del juicio, es de enorme importancia, porque llama nuestra atención acerca de la posibilidad de que no todo tránsito del Yo al Nosotros fuese suficientemente veraz. Para Kant, la suplantación del Otro o del Nosotros no pasaría de ser un caso singular de anomalía en el que, sin embargo, se seguiría reconociendo (tal es la grandeza del punto de vista trascendental) que incluso para el rey/dictador (digamos, para el ego entronizado y egocéntrico) seguiría siendo decisivo alcanzar la legitimidad que sólo el Nosotros podría conceder: como del mismo modo se ha de reconocer la relevancia trascendental del Yo. En el caso de la propuesta kantiana de la segunda máxima, el Nosotros sólo

${ }^{14}$ KANT, Immanuel: Antropología desde un punto de vista pragmático, Alianza Editorial, Madrid, 1991, pág. 20. 
alcanzaría verdadera legitimidad en tanto pudiera ser validado universalmente y si pudiera ser tensionado por la tercera máxima, que exige del yo la validación del esfuerzo racional del role-taking.

En el caso de la propuesta de Benhabib, a la que ahora me refiero, no se pretende retornar al Yo, sino más bien encontrar un camino veraz hacia la diferencia singular y encarnada del Otro.

\section{Ponerse en lugar del Otro y crítica al universalismo Sustitutivista}

En efecto, la contribución de Seyla Benhabib a las tres máximas kantianas (a las que no se refiere) es decisiva en el sentido de que, así como Kant se ha preocupado de confrontar el ponerse en el lugar del Otro con el sujeto como punto de partida (pensar por sí mismo) y como punto de llegada (pensar de acuerdo consigo mismo), Benhabib se centra en el segundo momento, cuestionando si con ese ponerse en el lugar del Otro se alcanzaría de veras el descentramiento necesario, pudiéndose deber el fracaso, en tal sentido, a alguna mala praxis involuntaria, o bien a la mala voluntad del sujeto al que se le demanda ponerse en lugar del Otro. En buena medida, la crítica de Benhabib ${ }^{15}$ conecta concretamente con la problemática general del feminismo, en la medida en que justamente el punto de vista de la mujer o de las mujeres no haya

\footnotetext{
${ }^{15}$ Pienso especialmente en BENHABIB, Seyla: "El Otro generalizado y el Otro concreto. La controversia Kohlberg-Gilligan y la teoría feminista", en Benhabib, Seyla y Cornell, Drucilla (eds.): Teoría feminista y Teoría crítica, Edicions Alfons El Magnànim (Institució Valenciana D’Estudis i Investigació), Valencia, 1990. Págs. 119-149. Hay otra traducción en el volumen El ser y el otro en la ética contemporánea. Feminismo, comunitarismo y postmodernismo, Gedisa, Barcelona, 2006, pero estimo que la primera es más correcta -y en lo sucesivo citaré con ella. El título original de esta obra es Situating the self. Gender, Community and Postmodernism in contemporary Ethics, Routledge, Nueva York, 1992.
} 
sido ni sea suficientemente asumido descentradamente por el varón, que aduce con frecuencia la universalización como criterio fuerte (respecto a las posibilidades del juicio moral) dejando, de este modo, eclipsada la diferencia encarnada de la mujer, como si esta diferencia pudiera ser obviada, "solventada" o "resuelta" sin más en lo que sería un universalismo de pacotilla o incluso, si se me permite la expresión, "de cartón piedra".

El reproche de Benhabib se dirige a lo que denomina universalismo sustitucional o sustitutivista [substitutionalist]. Quizás habría sido más adecuado hablar de "suplantación" en lugar de "sustitución". Resumidamente: el reproche consiste en que cada vez que el yo o un grupo afirma "Pensamos que...", puede ocurrir que se suplante a los que debieran tener voz propia, escamoteándoles su diferencia, con lo que sería del todo razonable que pudiesen elevar un reproche o la protesta de que ese "Nosotros" no estuviese probado ni fuese veraz ni representativo. Para Benhabib la teoría ética de la justicia parece centrarse en sujetos desarraigados y desencarnados (como en la teoría de la justicia de Rawls), lo que prefigura la distribución de roles de modo que el punto de vista de la mujer queda devaluado. La tesis de Benhabib se inserta en una problemática relativa a la confrontación entre Gilligan y Kohlberg, con vistas a evaluar la relevancia de la mujer en el terreno de la filosofía moral. Kohlberg se habría basado en una zona de la vida moral centrada en la ética de la justicia y de los derechos ${ }^{16}$, sin reconocer, como Gilligan, la ética del cuidado y de la responsabilidad. Así pues: mientras que el varón es más capaz de lo universal, a base de desarraigar y desencarnar (y Kohlberg centra en ello la capacidad para el juicio ético en torno a la justicia y los derechos), "el juicio moral de las mujeres es más contextual, está más inmerso en los detalles de las relaciones y las narrativas. Muestra una mayor propensión a adoptar el punto de vista del "otro

${ }^{16}$ Ibid., pág. 120. 
particular", y las mujeres parecen más duchas en revelar los sentimientos de empatía y simpatía que esto exige". Y de inmediato, he aquí lo que pretende Benhabib: "una vez que estas características cognitivas no son consideradas como deficiencias sino como componentes esenciales del razonamiento moral adulto en el estadio postconvencional, la aparente confusión moral de juicio de las mujeres se convierte en un signo de su fuerza" ${ }^{\text {". }}$. Así pues, Benhabib propone distinguir entre lo que llama "universalismo sustitutivista" y "universalismo interactivo"18. Mientras que en el primero se diferencia a un grupo específico como paradigmático de todos los seres humanos (Benhabib añade: adultos, blancos, varones, propietarios o al menos profesionales), el segundo se caracteriza por su compromiso con el pluralismo. En el universalismo interactivo, la universalidad es un ideal regulativo que no excluye nuestra identidad incardinada y arraigada. Y añade Benhabib: "La universalidad no es el consenso ideal de Sí-mismos definidos ficticiamente, sino el proceso concreto en política y en moral de la lucha de los sí mismos concretos e incardinados que se esfuerzan por su autonomía"19.

Benhabib apunta, de este modo, a criticar la prepotencia de la figura del "Otro generalizado" 20 contraponiéndola con la del "Otro concreto". Se trata de una problemática que implica a casi todos los

\footnotetext{
${ }^{17}$ Ibid., págs. 120-121.

${ }^{18}$ Lo que sin duda debería formar parte del proyecto al mismo tiempo cognitivo, ético y político de una democracia deliberativa -pero dejaré esta cuestión para una ocasión más propicia. Sí quisiera llamar la atención respecto a la importancia creciente que está alcanzando en el pensamiento político la llamada a una Democracia que no se base en la indiferencia de sus miembros, sino que, justamente, la reconozca. Pienso ahora, por ejemplo, en Nancy, Jean-Luc: La verdad de la democracia, Amorrortu, Buenos Aires, 2009.

${ }^{19}$ BENHABIB, Seyla: op. cit., pág. 127.

${ }^{20}$ BENHABIB (ibid., pág. 135, nota) advierte que aunque utiliza esa expresión, lo que con ella quiere significar difiere del significado que le otorgó George Herbert Mead en su Mind, Self and Society (1934).
} 
problemas filosóficos relativos a la intersubjetividad. Para Benhabib, en relación al Otro generalizado hacemos abstracción de la individualidad y la identidad concreta del Otro, de modo que $s u$ dignidad no conecta con lo que constituye su diferencia, sino justamente con aquello que tiene en común con nosotros en tanto agente(s) racional(es). De este modo, nuestra relación con ese Otro se rige por normas de igualdad formal y reciprocidad.

Ya hemos dicho que, en verdad, esto era lo que cabía esperar según nuestro primer desarrollo psico-evolutivo y de construcción de sentido común, por lo que superar, como pretende Benhabib, a este "Otro generalizado" en favor de un "Otro concreto" supone justamente que se "reoriente" nuestra "percepción" del Otro. Por ello,

el punto de vista del otro concreto, por el contrario, nos demanda considerar a todos y cada uno de los seres racionales como un individuo con una historia, una identidad y una constitución afectivo-emocional concretas. Al asumir este punto de vista hacemos abstracción de lo que constituye lo común. Intentamos comprehender las necesidades del otro, sus motivaciones, qué busca y cuáles son sus deseos. Nuestra relación con el otro es regida por las normas de equidad y reciprocidad complementaria: cada cual tiene el derecho a esperar y suponer de los otros formas de conducta por las que el otro se sienta reconocido y confirmado en tanto que ser individual y concreto con necesidades, talentos y capacidades específicas. En este caso nuestras diferencias se complementan en lugar de excluirse mutuamente. Las normas de nuestra interacción suelen ser privadas, no institucionales. Son normas de amistad, amor y cuidado. Estas normas exigen de varias formas que yo exhiba algo más que la simple afirmación de mis derechos y deberes de cara a tus necesidades. Al tratarte de acuerdo con las normas de amistad, amor y cuidado, no sólo confirmo tu humanidad sino también tu individualidad humana ${ }^{21}$

${ }^{21}$ Ibid., pág. 136. 
Como ya se dijo, Benhabib no pretende eliminar la perspectiva universalista, sino compensar críticamente las poderosas tendencias sustitutivistas o de suplantación, que son proyectivonarcisistas y tienden a eliminar justamente el punto de vista en el que el Otro no es uno más ni de "los nuestros", sin su propia diferencia específica. En verdad, aquel "ponerse en lugar del Otro" puede convertirse en un perjuicio para el Otro mismo, es decir, para el Otro en la diferencia que le hace ser Otro. Es preciso comprender que para ponerse en lugar del Otro hay que efectuar lo que se pretende, sin eclipsar o disimular al Otro en su "ser por sí mismo".

\section{Algunas cuestiones prácticas o de aplicación}

Quien quiera que indague en algún manual de psicología evolutiva que aborde el role-taking comprobará la ingente cantidad de prácticas y experimentos encaminados a objetivar el desarrollo cognitivo, social o ético del niño siguiendo el hilo conductor del descentramiento. Para un filósofo casi puede llegar a resultar decepcionante, en algunos casos, que la enorme energía y creatividad desplegada en tales experimentos, propios, como cabía imaginar, de una psicología que en muchas ocasiones se postula como un saber positivo y empírico que busca intervenir del modo más concreto posible sobre el psiquismo en sus vínculos cognitivos, sociales, educativos, éticos, etc., no sea acompañada de una reflexión con mayor profundidad teórica.

De cara a la asimilación filosófica del role-taking en el horizonte de una Filosofía aplicada, los ejemplos o prácticas serían igualmente abundantes, hasta tal punto estamos ante un dinamismo esencial. En nuestro caso, y por volver al comienzo de este artículo, pienso que lo que estaría en juego en dichas prácticas sería: a) percatarnos, si no de nuestra propia evolución psicológica, que nos puede resultar inaccesible, sí al menos, a título de lucidez 
hermenéutica, de la situación de partida en el sentido común compartido como suelo básico de la comprensión/interpretación en el seno de un Nosotros; en buena medida, las investigaciones de Schütz en torno a la construcción del sentido común permitirían esclarecer la estructura prejuicial de la comprensión en la hermenéutica gadameriana; y b) que por más que el role-taking represente un privilegio (en función del cual estará nuestra "inteligencia" y "creatividad" o "sentido de la justicia"), sin embargo, no es suficiente el haber previo, pues junto al Nosotros de partida, el sujeto racional y ético requiere ser inquietado por lo que se refiere a la potencial insuficiencia de un role-taking no ejercitado en una esforzada práctica. Por tanto, podría formar parte de un programa de prácticas filosóficas la necesidad de vislumbrar las situaciones "hermenéuticas" de partida (desde las más genuinamente racionales hasta aquellas en las que más elaborada y profundamente estuviese implicada la inteligencia emocional) en la medida en que, lejos de avalar un conformismo, por el contrario, incitasen la exigencia de ejercitarse en un "ponerse en el lugar del Otro" que dejara de ser un logro ya alcanzado, obvio, pudiendo encubrir perturbaciones y desviaciones que pondrían en peligro el encuentro (y por tanto el diálogo) con el Otro. Y todo ello, con las miras puestas en que frente al Nosotros de partida pudiera erigirse otro Nosotros como "comunidad de comunicación" más crítica y con más y nuevas opciones, concretamente, en el horizonte de lo que llamó Habermas ética del discurso ${ }^{22}$.

${ }^{22}$ HABERMAS, J.: La ética del discurso y la cuestión de la verdad, Paidós, Barcelona, 2003, págs. 22-24: "La transición de una reflexión monológica al diálogo pone de manifiesto un rasgo del procedimiento de universalización que permaneció implícito hasta el surgimiento de una nueva forma de conciencia histórica, a caballo entre el siglo XVIII y el XIX. Tan pronto como percibimos la historia y la cultura como fuentes de una abrumadora variedad de formas simbólicas, y de la singularidad de las identidades individuales y colectivas, también nos damos cuenta del reto que supone, en consecuencia, el pluralismo epistémico. Hasta cierto punto, el hecho del pluralismo cultural significa también 
Así pues, una primera fase o grupo de prácticas demandaría 1) rehacer cierta lucidez acerca del Nosotros en que participamos bajo la modalidad de un "estar ya puestos entre nosotros en lugar del Otro" en cada caso, de modo que al mismo tiempo que el creer poder ponerse en el lugar de Otros también presupone, en virtud de la reciprocidad de que hablaba Schütz, que estos Otros puedan ponerse en mi lugar. En una segunda fase, ganaría mayor relevancia 2) el cuestionamiento crítico de lo que en esta expresión predada del role-taking se presupone sin suficiente legitimidad. Para ello, habría que introducir la posibilidad de una especie de decepción terapéutica, para la que habría que activar experiencias de desestabilización y críticas respecto a lo que damos por presupuesto. Estas experiencias no tratarían, en absoluto, de cuestionar psicológica, social o trascendentalmente la importancia

que el mundo es percibido e interpretado globalmente de formas distintas desde la perspectiva de individuos distintos y grupos distintos (al menos en principio). Existe una especie de pluralismo interpretativo que afecta a la visión del mundo y a la comprensión de uno mismo, al tipo y a la relevancia de los valores y los intereses que perciben las personas, cuya historia vital se halla impregnada en tradiciones y formas de vida particulares, y es configurada por ellas.

Esta multiplicidad de perspectivas interpretativas es la razón por la cual el significado del principio de universalización no queda suficientemente agotado por ninguna reflexión monológica a partir de la cual las máximas serían aceptables, desde mi punto de vista, como ley general. Sólo como participantes en un diálogo inclusivo y orientado hacia el consenso se requiere de nosotros que ejerzamos la virtud cognitiva de la empatía hacia las diferencias con los otros en la percepción de una situación común. Se supone que debemos interesarnos por cómo procedería cada uno de los demás participantes, desde su propia perspectiva, para la universalización de todos los intereses implicados. El discurso práctico puede interpretarse así como un modelo para la aplicación recurrente del imperativo categórico. Los participantes en la discusión no pueden esperar alcanzar un acuerdo acerca de aquello que responde igualmente a los intereses de todos, a menos que se sometan al ejercicio de una "toma de perspectiva mutua", que llevaría a lo que Piaget llama un "descentramiento" progresivo de la propia comprensión ego y etnocéntrica de uno y el mismo mundo". 
del role-taking, sino de perfeccionarlo no como un hecho, sino como una virtud. Por eso, se trata de una decepción metódica, "programada", y siempre con vistas a perfeccionar las posibilidades racionales y éticas a) del yo que se pone en lugar del Otro, y b) del Otro que se ponga en mi lugar. Lo que hemos querido decir en los cuatro apartados anteriores es que junto a la fase más pasiva (infancia, según la psicología evolutiva, y sentido común en Schütz) debe haber una más activa, sea que se aspire a culminar en la convicción de autonomía del sujeto racional (Kant), o bien en un fortalecimiento de la demanda de reconocimiento del Otro como realmente Otro, diferente y potencialmente disidente de la perspectiva del yo (Benhabib). Concretamente, el mayor nivel de lucidez crítica se alcanza en la apuesta de Benhabib como descenso a lo concreto, descenso postconvencional, ciertamente, y postuniversalista-sustitutivista, entendiendo este universalismo como ingenuo, en favor de un universalismo más lúcidamente crítico o, como dice Benhabib, interactivo, o también críticamente inclusivo.

A título práctico, podrían proponerse como situaciones de partida algunas en las que pueda comprobarse fácilmente el automatismo del role-taking pudiéndose, al mismo tiempo, suscitar dificultades cuando no se opere "endogrupalmente", es decir, desde el inmediato interior de la reciprocidad de perspectivas consolidada. Pensemos en comunidades de edad, de género, de creencia, de etnia o de ideología. En general, habrá que comprender en qué medida el role-taking como hecho y como virtud viene exigido en todos los niveles de nuestra experiencia. Por ejemplo, la madre tiene que ponerse en lugar del hijo (aunque -permítaseme decirlo- también el hijo en lugar de la madre), el cuidador en lugar de quien tiene a su cargo ${ }^{23}$, el profesor en lugar del alumno $-\mathrm{y}$ en

${ }^{23}$ Me ocupé de este tema en "Estima de sí y dignidad en la bioética de Paul Ricoeur", en DOMINGO MORATALLA, T. y DOMINGO MORATALLA, A. (eds.): Bioética y Hermenéutica: La ética deliberativa de Paul Ricoeur. Actas Congreso Internacional, Campgràfic Editors, Valencia, 2013. Págs. 421-429. 
menor intensidad en el caso contrario ${ }^{24}$-, el médico en lugar del enfermo, el juez en lugar del encausado o de la víctima, el director en lugar de sus dirigidos... El role-taking exige un compromiso epistémico y ético en el que la responsabilidad puede encontrarse desigualmente repartida (lo que no es nada infrecuente). En otros casos, esta desigualdad no es (o no debiera ser) tan relevante, como en las relaciones de pareja, de amistad o colaboración ${ }^{25}$.

Pensemos, sólo a modo ejemplo, en ocasiones en que sea relevante en una argumentación la diferencia de edad, en la medida en que no se trata meramente de un hecho psicológico-evolutivo, sino un modo de realizarse en cada caso nuestro ser en el mundo. En cuántas ocasiones es esta diferencia la que se interpone, con frecuente dramatismo y tentaciones de dogmatismo, en conflictos intergeneracionales, agudizándose en la zona de edad de la adolescencia, o en la de tercera edad (más concretamente, ancianidad, senilidad con dependencia). El adolescente tiende a enfrentarse a todo lo que $y$ a todo aquel que quiera sustituirle/suplantarle, precisamente porque se encuentra en una edad en la que aspira a una voz propia. En otro caso, muy diferente, el de la relación con la ancianidad, puede presentarse en toda su intensidad la tentación no ya de ponerse en el lugar del Otro, sino, sin tapujos ni medias tintas, de suplantarle (bajo la forma, por ejemplo, de tomar decisiones relevantes sin contar con la persona anciana). O, valga otro ejemplo, en la relación del que se considera "civilizado" respecto al tenido por "salvaje". O en casos de

\footnotetext{
${ }^{24}$ Lo que no sería de poca importancia de cara al reconocimiento de la autoridad del docente, por ejemplo.

${ }^{25}$ En otros casos, la desigualdad se incrementa. También es preciso practicar el role-taking respecto a nuestra relación con el animal, cada día más antropológicamente relevante. Es necesario ponerse en su lugar a sabiendas de que la relación es asimétrica (con vistas a comprender que se trata justamente de un animal, despojando la comprensión de su comportamiento de frecuentes connotaciones antropomórficas).
} 
conflicto multicultural, o con vistas a la optimización de las posibilidades de un encuentro intercultural. Verdaderamente, en algunos casos (que son los que deben ser especialmente tenidos en cuenta), cuando el role-taking funciona sin suficiente reserva autocrítica, opera de un modo no ya ineficaz, sino claramente perjudicial e incluso premeditadamente abusivo. Sin embargo, en algunas ocasiones, y en ello se constata que se trata de un problema epistémico, y no tanto de buena o mala voluntad, simplemente no se repara en que el "ponerse en lugar del Otro" debe operar contando con la capacidad expresiva del Otro mismo, es decir, que sólo puede operar eficazmente si previamente en verdad se ha aceptado y accedido a su diferencia, como tal, antes de e incluso más allá de la posibilidad del consenso.

El conflicto que suscita el dinamismo del role-taking guarda relación justamente con el poder que alcanza el prejuicio para prefigurar nuestras opciones de pre-comprensión. Siendo como es un recurso benéfico y fundamental en el desarrollo psico-social, se trata de un dinamismo en el que, antes de llegar a ser una esforzada disciplina racional, nos hemos "asentado" psicológica y socialmente, sin cuestionarlo usualmente (siendo así como, en principio, "debe" ser), sin que este no-cuestionamiento fuese un demérito ni propiamente un mérito, sino, más sencillamente, un mero hecho psicológico y social a modo de nivel pasivo básico de pre-consenso eficaz. Ello justifica que tenga tanta importancia que se insista no sólo en el automatismo del estar ya puestos en el lugar del Otro, sino en las dificultades, entre las que se cuentan (y son de las más importantes) las tentaciones de malversación de esa "habilidad". Este es el tema que debe ser pensado en el horizonte de una Filosofía aplicada: el de la evaluación de los prejuicios hermenéuticos que resultan del role-taking con vistas no sólo a reconocerlos, sino a cuestionarlos críticamente de cara a no tergiversar el potencial de diferencia y disenso de los Otros. 
Propiamente, la experiencia del role-taking es, como hemos dicho, originalmente previa al diálogo. Cuando lo abordamos a) debemos reconocer nuestra ubicación prejuicial heredada o fáctica; b) pero también la del Otro, con lo cual al mismo tiempo c) favorecer que se relativice nuestra ubicación; d) de modo que en la medida en que aspiremos a ponernos en lugar del Otro será porque aspiremos, no tanto a superar nuestra ubicación, cuanto a conocer la del Otro e intentar que puedan componerse y compensarse los Aquí respectivos, o los correspondientes sistemas de significatividades; y (esto me parece especialmente interesante) e) sin necesidad perentoria de forzar un consenso y, menos aún, de, a toda costa, tender a "universalizar". En el propio Kant, el sensus communis debe culminar en el retorno del sujeto racional como reforzamiento de una autonomía crítica... con lo que la relevancia no se reduce a alcanzar un acuerdo "feliz"... Y en Benhabib, más aún, justamente se trata de cuestionar que pueda transitarse a la universalización sin un esmerado, meticuloso y ultra-auto-crítico paso por esa capacidad que hemos heredado pero que siempre se encuentra expuesta a su malversación o a su abuso, por lo que sería necesario encontrar la oportunidad de atender a la concreción individual, vital y encarnada del Otro.

Sólo entonces, en el caso de que el consenso no fuese posible, al menos habríamos llegado a comprender que el disenso estaba fundado en la verdad de la comprensión recíproca de los interlocutores (o incluso: en el intento esmerado de esa comprensión), lo que ya supone un logro inmenso. Para ello, me parece imprescindible incorporar a las dimensiones psico-social y de sentido común del role-taking, tanto el retorno kantiano al Yo como la insistencia benhabiana en el Otro concreto. 


\section{Bibliografía}

BENHABIB, S.: El otro generalizado y el otro concreto. La controversia. Kohlberg-Gilligan y la teoría feminista, en BENHABIB, S. y CORNELL, D. (eds.): Teoría feminista y teoría crítica. Ensayos sobre la política de género en las sociedades de capitalismo tardio (trad. de A. SÁNCHEZ), Edicions Alfons el Magnànim (Institució valenciana d'estudis i investigació), Valencia, 1990. Págs. 119-149. Edición en lengua inglesa: BENHABIB, S.: Situating the Self. Gender, Community and Postmodernism in Contemporary Ethics, Routledge, Nueva York, 1992.

BENHABIB, S.: El Ser y el Otro en la ética contemporánea. Feminismo, comunitarismo y postmodernismo (trad. de G. ZADUNAISKY), Gedisa, Barcelona, 2006.

GADAMER, H.G.: Verdad y método. Fundamentos de una hermenéutica filosófica (trad. de A. AGUD y R. De AGAPITO), Sígueme, Salamanca, 1977.

HABERMAS, J.: La ética del discurso y la cuestión de la verdad (trad. de R. VILÁ), Paidós, Barcelona, 2003.

HEIDEGGER, M.: Ser y tiempo (ed. a cargo de J. E. RIVERA), Trotta, Madrid, 2009.

KANT, I.: Crítica del juicio (trad. de M. GARCÍA MORENTE), Espasa-Calpe, Madrid, 1977.

Antropología desde un punto de vista pragmático (trad. de J. GAOS), Alianza Editorial, Madrid, 1991.

LEBRUN, G.: Kant y el final de la metafísica. Ensayo sobre la Crítica del juicio, Escolar y Mayo, Madrid, 2008.

MARCHESI, A.: "El pensamiento preoperatorio", en PALACIOS, J., MARCHESI, A. y CARRETERO, M. (comps.): Psicología evolutiva 2. Desarrollo cognitivo y social del niño, Alianza Editorial, Madrid, 1985. 
MEAD, G.H.: Mind, Self and Society, University of Chicago Press, Chicago, 1934.

MINGO RODRÍGUEZ, A.M.: "Estima de sí y dignidad en la bioética de Paul Ricoeur", en DOMINGO MORATALLA, T. y DOMINGO MORATALLA, A. (eds.): Bioética y Hermenéutica: La ética deliberativa de Paul Ricoeur. Actas Congreso Internacional, Campgràfic Editors, Valencia, 2013. Págs. 421-429.

PIAGET, J.: El lenguaje y el pensamiento del niño pequeño, Paidós, Barcelona, 1984.

SCHÜTZ, A.: El problema de la realidad social (ed. a cargo de M. Natanson), Amorrortu, Buenos Aires, 1974. Edición original: BRYSON, LYMAN, FINKELSTEIN, LOUIS, HOAGLAND, HUDSON y MACIVER, R.M. (eds.): Symbols and Society (Símbolos y Sociedad. Actas del $14^{\circ}$ Simposium de la Conferencia sobre Ciencia, Filosofía y Religión), Harper, New York, 1955.

SELMAN, R.L.: "Taking another's perspective: Role-taking development in early childhood", en Child Development, volume 42, 1971. 